\title{
Contribution of Turkish Scholars to Earthquake Literature: The Impact of the Marmara Earthquake
}

\author{
Zehra TASKIN \\ Hacettepe University Department of Information Management 06800 Beytepe ANKARA. zehrayanar@gmail.com
}

\begin{abstract}
This paper addresses the question of whether the Marmara Earthquake of August 17, 1999 has had an impact on the contribution of Turkish scholars to the earthquake literature. We identified a total of 1,098 papers published between 1990 and 2009 by Turkish earthquake scientists. These papers were cited 7,691 times. Both the number of papers and the citations they generated have increased considerably after the Marmara Earthquake. This may be explained, in part, by the increase in the number of projects being carried out since then to study the Marmara Sea basin.
\end{abstract}

Keywords: Marmara Earthquake, citation analysis, Turkish earthquake literature

\section{Introduction}

Due to its geographical position, there have been many earthquakes in Turkey throughout the history. The Marmara Earthquake of August 17, 1999 was one of the most destructive earthquakes in recent history. It measured 7.4 on the Richter scale and affected mainly the urban dwellers living in Istanbul and its environs (Ozerdem, 1999). According to the initial reports, the earthquake resulted in approximately 15,226 fatalities and 23,983 injured. In addition to mortalities and injuries, it caused US \$9-13 billion property damage. It was estimated that 14,444,298 inhabitants living in the Marmara region were affected by the event. The Marmara Earthquake have had negative effects on the Turkish industry, education and health system, labor force, agriculture and infrastructure (T.R. Prime Ministry State Planning Organization, 1999).

This paper reviews the effects of the Marmara Earthquake on the number of publications authored by Turkish scholars. It identifies the most productive authors and institutions carrying out earthquake research in Turkey.

\section{Problem Statement}

The main aim of this study is to evaluate the papers on earthquake authored by Turkish scholars between 1990 and 2009 and determine the impact of the Marmara Earthquake of 1999. The hypothesis of this study addressed is: "The number of publications authored by Turkish scholars in earthquake field has been increased after Marmara Earthquake of 1999". More specifically, this study attempts to answer the following research questions:

- What types of publications are published by Turkish earthquake scientists?

- What percentage of the world's earthquake literature is generated by Turkish scholars?

- Who are the most productive authors and institutions carrying out research on earthquake in Turkey?

- Where do Turkish earthquake scientists publish and how often are their works cited?

\section{Literature Review}

There have been many papers about bibliometric analysis of publications in a specific field (Ding, Chowdhury, \& Foo, 2000; Zhang, 1998; Burright, Hahn, \& Antonisse, 2005; Qui, \& Chen, 2009). Earthquake literature doesn't include any work directly relevant to citation analysis. However, there are three such articles on seismic studies and earthquake engineering.

Some 1128 papers published by the Institute for Geophysics of University of Texas were evaluated in a study (Frohlich \& Resler, 2001). Papers were classified into four categories that differed significantly with respect to statistics such as lifetime citation rates, fraction of papers never cited after 10 years and cited half-life. It was concluded that reported differences in cited half-lives must be quite large to be significant. 
Trifunac (2006b) analyzed the works of 51 academics for the aim of finding influential researchers on earthquake engineering. He used ISI's HighlyCited.com and tried to find out why there are no earthquake engineers in the category of engineering. As a result, the earthquake engineering was absent in the engineering category of ISI's HighlyCited.com. Trifunac also compared female and male academics in earthquake engineering by using citation analysis methods (Trifunac, 2006a).

Studies on bibliometrics and citation analysis have also been published in Turkey. They generally examined dissertations (Tonta \& Al, 2006; Uçak \& Al, 2009a; Uçak \& Al, 2009b; Bayram, 1998).

Some 572 Turkish physics publications that were appeared in Science Citation Index between 1982 and 1990 were evaluated in a study (Uzun, Menard \& Özel, 1993). As a result, they found that papers from Turkey that have been published in European or American Journals are cited higher.

Hacettepe University addressed papers published between 1975 and 2003 were appraised in 2004 (Al, Al \& Bahşişoğlu, 2004). Science Citation Index and Journal Citation Reports were used as data tools and 9688 publications were analyzed. As a conclusion, over one third of publications were published after 2000. Almost all of publications were written in English. Four and more than four-author publications constituted 57\% of all publications. Only 8\% of publications had single authorship.

There are a few studies for the combination of the earthquake and citation analyses in the world. However, Turkey hasn't published yet. This is the first study based on citation analysis of papers on earthquake in Turkey.

\section{Methodology}

ISI Web of Science has been used as a data tool for this study. Data have been collected from Science Citation Index (SCI), Social Sciences Citation Index (SSCI), Conference Proceedings Citation Index - Science (CPCI-S) and Conference Proceedings Citation Index - Social Sciences (CPCI-SS) databases.

Searches were carried out on April 27, 2010. The term "earthquake" was used as search topic. Then, for the purpose of finding papers with addresses belonging to Turkish institutions, the terms "Turkey" or "Türkiye" were entered in the address field.

Data were analyzed by using "analyze results" and "create citation reports" options provided by the Web of Science (Thomson, 2007). In addition, Excel and SPSS software were used to create tables and charts.

\section{Findings}

\section{Publication Count and Citations}

We identified a total of 1,098 papers on earthquake published by Turkish scholars between 1990 and 2009 (Web of Science, 2010). These publications were cited 7,691 times and average citation per publication was 7 . The average citation per publication per year was 366,24. Figure 1 shows the graph of annual publication counts for Turkey and the world.

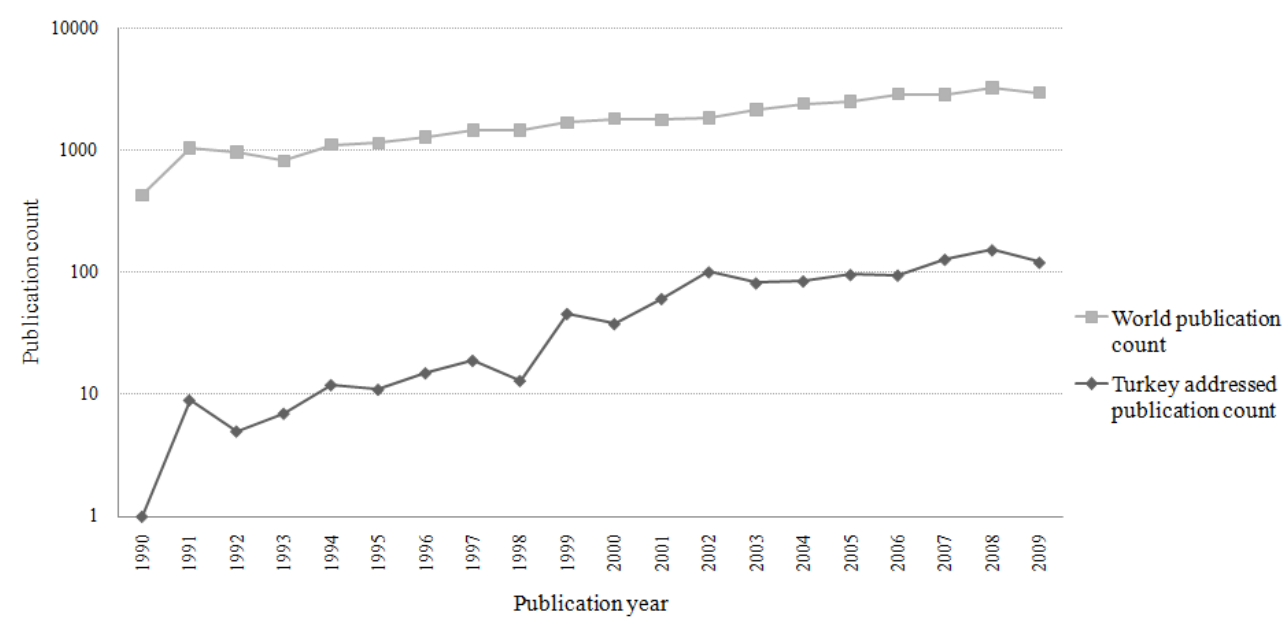

Fig. 1: The graph of publication count by year

Although the publication count had been relatively low until the end of 1990s, there has been a huge growth since the year 2000. Commensurate with the increase in the number of publications, the number of citations to papers by 
Turkish scholars has also increased tremendously since the year 2000 (Fig. 2). These figures clearly show that the number of papers and citations thereto have almost doubled after the Marmara Earthquake of 1999.

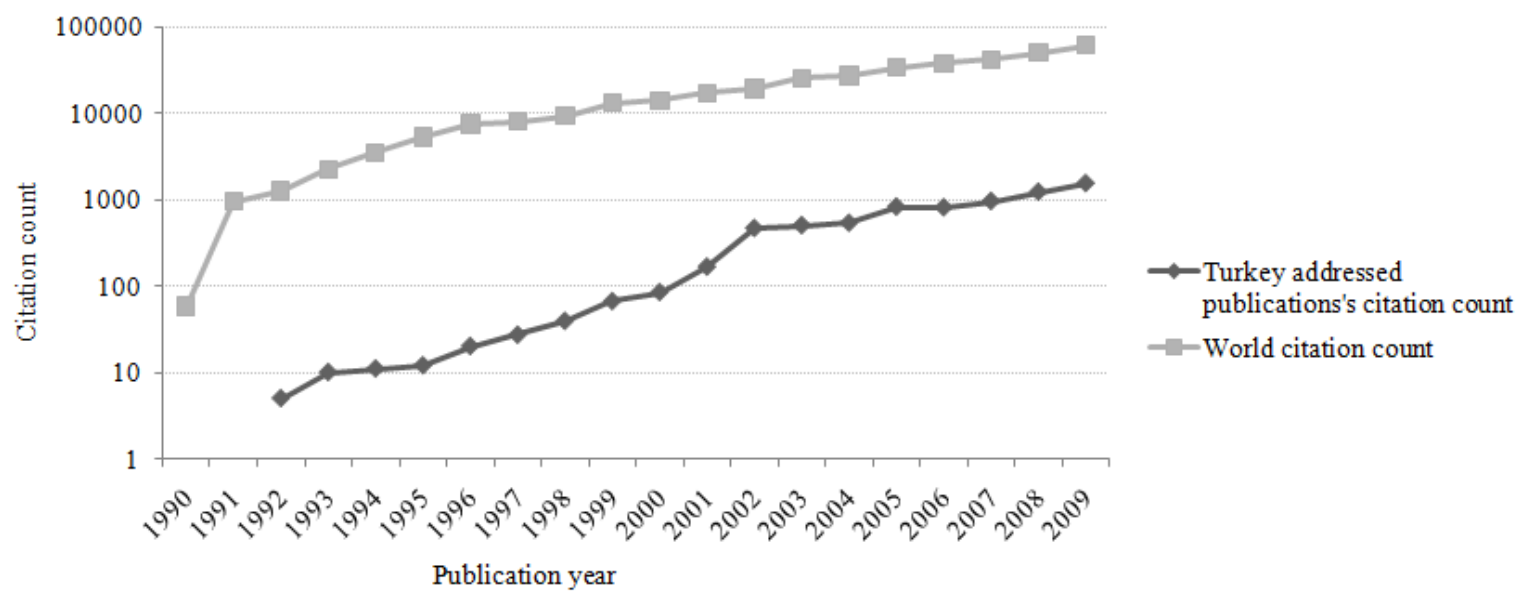

Fig. 2: The graph of citation count by years

Nearly 220 of publications are about Marmara Earthquake of 1999. Figure 3 clearly shows that the distribution of publications according to their subjects. 55\% of these publications were published between 2002 and 2005. Although almost all publications published in 2002 are about Marmara Earthquake, number of publications on this subject has decreased in recent years.

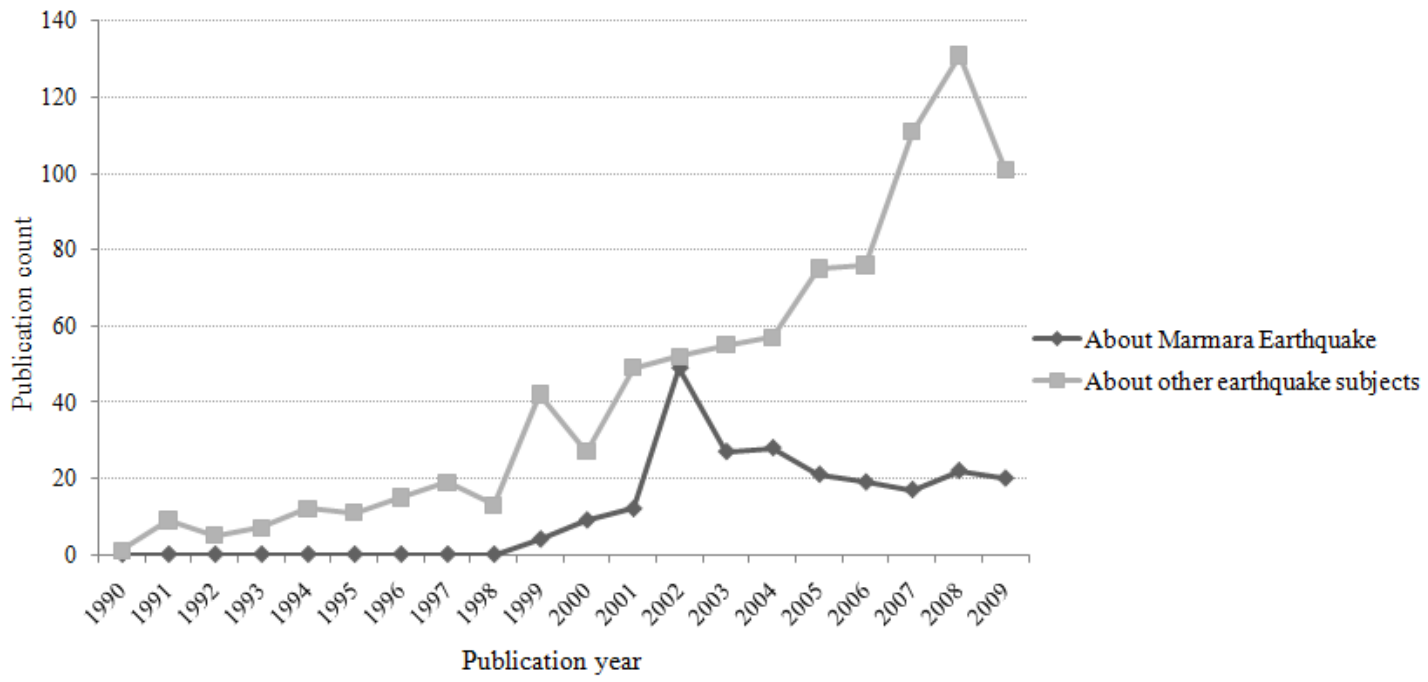

Fig. 3: Distribution of publications according to their subjects

Some $61 \%$ of publications were cited at least once. The rest have yet to be cited. Ten publications were cited more than 100 times. Figure 3 shows the distribution of publication and citation counts. 


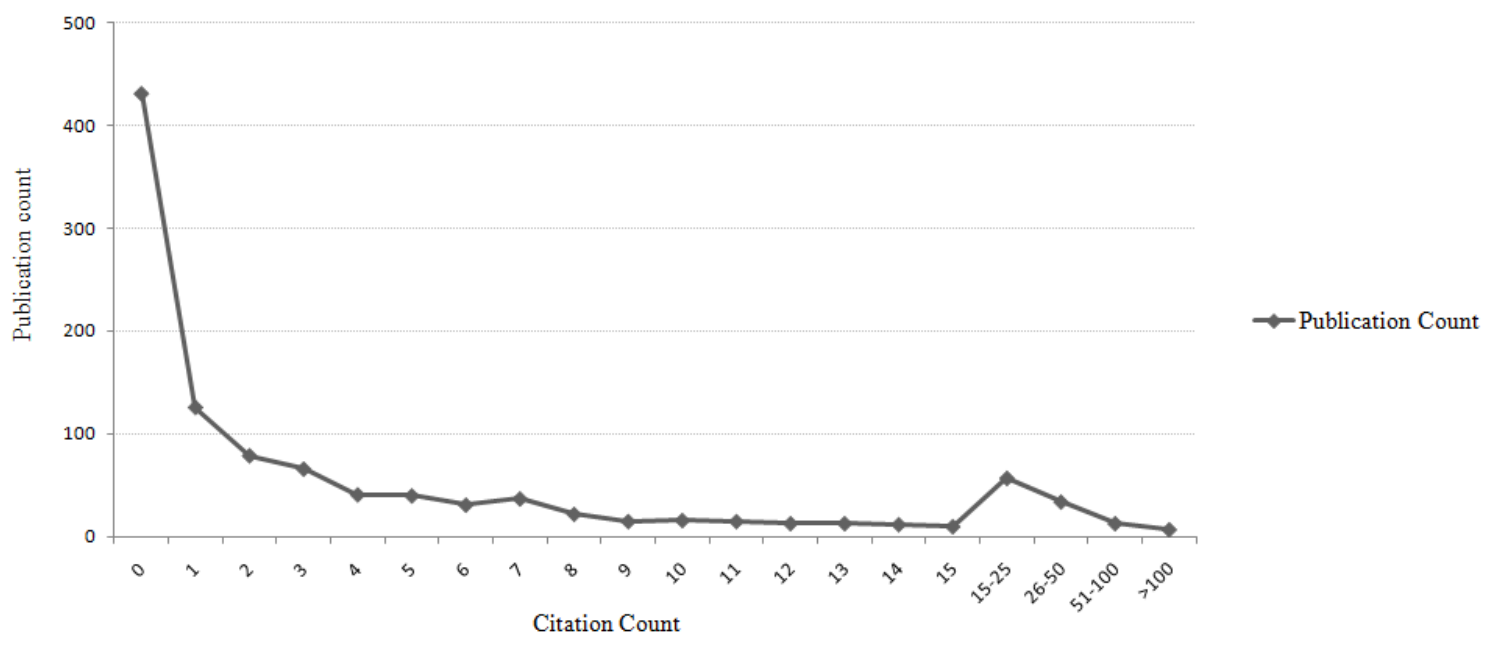

Fig. 4: Distribution of publications and citation counts

Nearly half the non-cited 431 publications were published in 2008 and 2009 (see fig. 4.), which means that they have the potential of generating citations in the coming years.

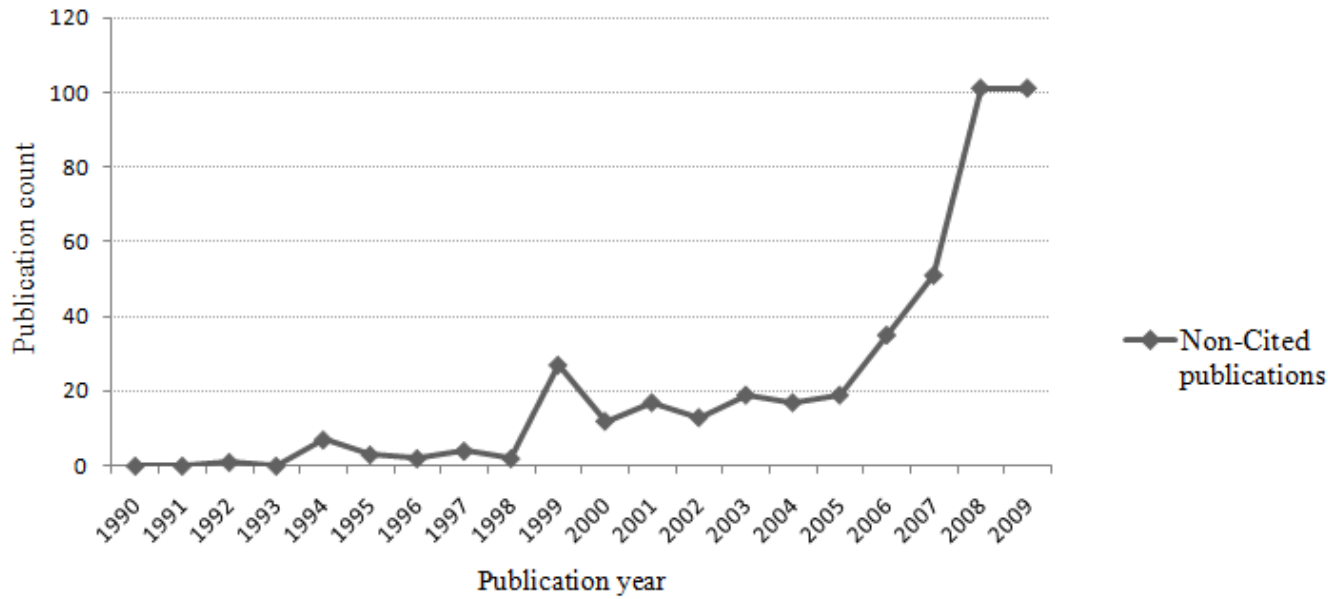

Fig. 5: Non-Cited publications and their publication years

\section{Publication types}

Almost three fourths of publications were journal articles. In addition to these articles, there are also proceedings papers, editorial materials and letters (see table 1.).

Table 1: Document types $(\mathrm{N}=1,098)$

\begin{tabular}{lcc}
\hline Document Type & N & \% \\
\hline Article & 823 & 74,9 \\
Proceedings paper & 215 & 19,5 \\
Editorial material & 26 & 2,3 \\
Letter & 14 & 1,2 \\
Review & 12 & 1,1 \\
Meeting abstract & 7 & 0,6 \\
Note & 1 & 0,1 \\
\hline
\end{tabular}

\section{Comparison between Other Countries}

Some 34,721 articles were published between 1990 and 2009 about earthquake in the world. USA ranks $1^{\text {st, }}$ generating one third of papers, while Turkey ranks $11^{\text {th }}$ in terms of contribution to the earthquake literature. The 
Turkish contribution made up only $1 \%$ of the world's earthquake literature before 1998, whereas it has quadrupled (4\%) after the Marmara Earthquake of 1999.

\section{Journals}

Over 7\% of all articles published by Turkish scholars appeared in one journal (Bulletin of the Seismological Society of America). The vast majority of journals published one or two articles from Turkish scholars. Journals publishing only one article constituted $60 \%$ of all journals in which contributions from Turkey appeared. Figure 5 shows the cumulative distribution of articles in accordance with journals.

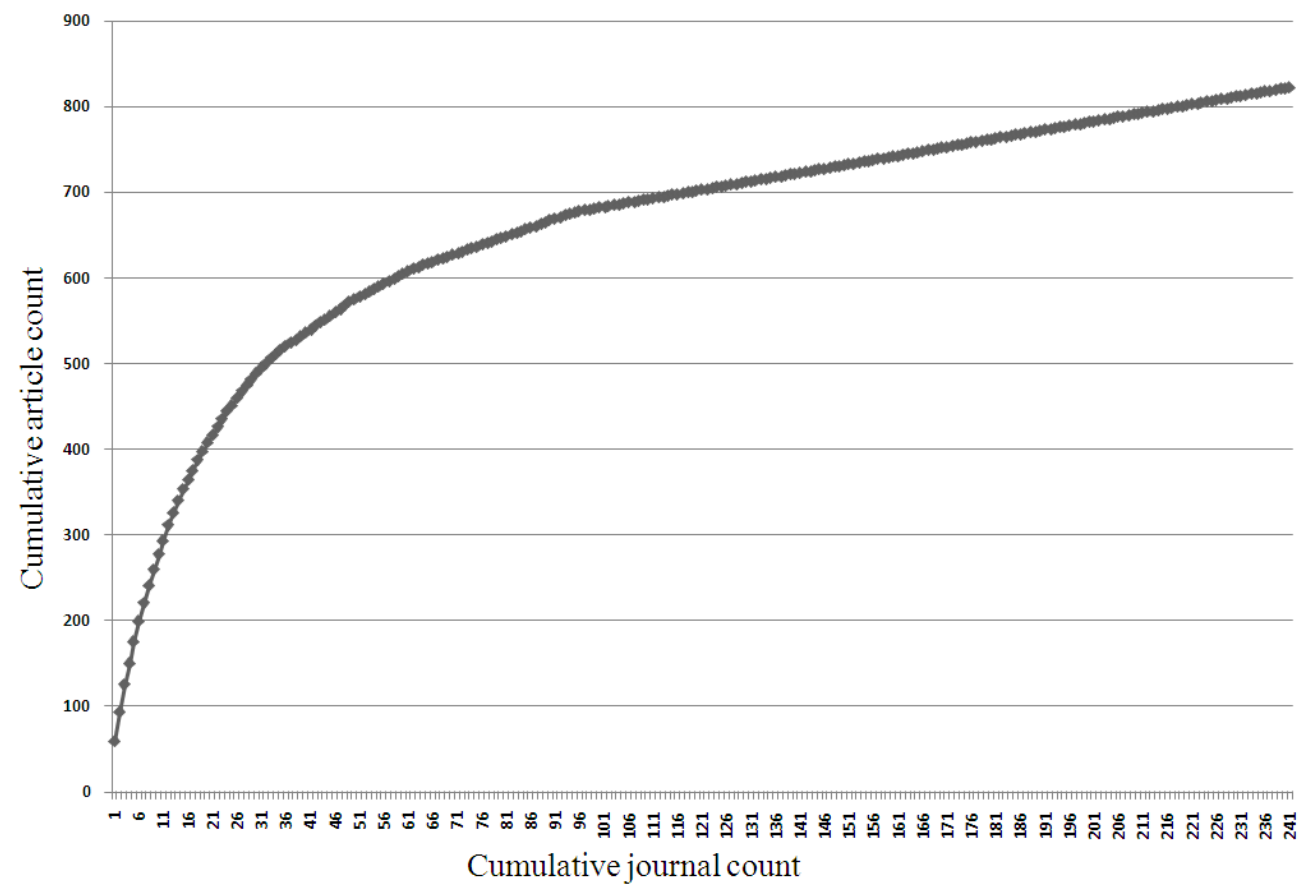

Fig. 6: Cumulative distributions of articles

Some 822 articles were published in 241 journals. The impact factor is a measure of the frequency with which the "average article" in a journal has been cited in a particular year or period. Journal Citation Reports (JCR) of Thomson Reuters provides journals' impact factors. The annual JCR impact factor is a ratio between citations and recent citable items published (Thomson Reuters, 2010). The most used journals and their impact factors are listed in Table 3. Turkish authors seem to have preferred international journals. They published only 12 articles in Turkish Journal of Earth Sciences and 9 in Teknik Dergi, both journals published in Turkey.

Table 2: Most used journals and their impact factors (JCR, 2008)

\begin{tabular}{lll}
\hline Journal's Name & $\begin{array}{l}\text { Number of } \\
\text { articles }\end{array}$ & $\begin{array}{l}\text { Impact } \\
\text { Factor }\end{array}$ \\
\hline Bulletin of The Seismological Society of America & 60 & 2,199 \\
Geophysical Journal International & 33 & 2,219 \\
Engineering Structures & 32 & 1,102 \\
Soil Dynamics And Earthquake Engineering & 26 & 1,182 \\
Engineering Geology & 25 & 1,197 \\
Structural Engineering And Mechanics & 23 & 0,500 \\
Earthquake Engineering \& Structural Dynamics & 21 & 1,240 \\
Natural Hazards & 21 & 1,142 \\
Journal of Seismology & 18 & 1,091 \\
Tectonophysics & 18 & 1,670 \\
\hline
\end{tabular}


Generally, journal articles were published by authors based in big universities of Turkey. Top five universities published over half the articles (see table 4).

Table 3: Top five universities for earthquake subject

\begin{tabular}{lcc}
\hline Institution Name & N & \% \\
\hline Bogazici University & 117 & 14,21 \\
Istanbul Technical University & 114 & 13,85 \\
Middle East Technical University & 107 & 13 \\
Istanbul University & 59 & 7,16 \\
Karadeniz Technical University & 57 & 6,92 \\
\hline
\end{tabular}

The most productive author was A. Bayraktar who published 27 articles. Dr. Aykut Barka, who died in 2002, ranked $3^{\text {rd }}$ with 21 articles published between 1996 and 2002 (see table 5).

Table 4: the most productive first ten authors

\begin{tabular}{lll}
\hline Author & N & \% \\
\hline Bayraktar, A & 27 & 3,28 \\
Erdik, M & 22 & 2,67 \\
Barka, A & 21 & 2,55 \\
Sever, MS & 20 & 2,43 \\
Aktar, M & 19 & 2,30 \\
Ergintav, S & 18 & 2,18 \\
Sucuoglu, H & 17 & 2,06 \\
Vanholder, R & 17 & 2,06 \\
Alptekin, O & 14 & 1,70 \\
Eyidogan, H & 14 & 1,70 \\
\hline
\end{tabular}

\section{Conclusion}

In conclusion, the number of publications authored by Turkish earthquake scientists has increase considerably since 1999. The main reason seems to be the Marmara Earthquake of 1999, as the publication and citation counts doubled since then. The contribution of Turkey to the world's earthquake literature quadrupled as well, placing Turkey in the 11 th rank among the world's countries. The hypothesis of this study is accepted.

Yet, papers by Turkish earthquake scientists have not been cited heavily in the literature. Very few papers have generated more than 100 citations while $60 \%$ of publications were cited at least once. Turkish earthquake scientists generally preferred international journals to publish their work, and $7 \%$ of their contributions appeared in a prestigious journal (Bulletin of the Seismological Society of America).

It is hoped that research earthquake carried out in Turkey will improve our understanding of devastating earthquakes not only in Turkey but elsewhere. If the current growth rate of publications on earthquakes continues, Turkey can be one of the top ten countries in the world conducting serious research on earthquake engineering.

\section{Acknowledgements}

I would like to thank Prof. Dr. Yasar Tonta for his very helpful comments, suggestions and improvements on this paper. 


\section{References}

Al, P., Al, U. \& Bahşişoğlu H. K. (2004). Science Citation Index'de Hacettepe Universitesi: 1975-2003 (Hacettepe University in the Science Citation Index: 1975-2003). Hacettepe Universitesi Edebiyat Fakultesi Dergisi, 21(2): 229-244, Aralik 2004. Retrieved November 28, 2009 from http://yunus.hacettepe.edu.tr/ umutal/publications/hu-sci-1975-2003.pdf

Bayram, Ö. (1998). Atıf Verisi ve Enformetrik Yasalar: Türk kütüphanecilik literatüründeki doktora tezleri üzerinde bir uygulama (Citation data and informetrics law: an application in doctoral theses to the Turkish Librarianship). Türk Kütüphaneciliği, 12(1): 21-32. Retrieved December 2, 2009 from http://www.kutuphaneci.org.tr/web/node.php?action=6\&type=6\&target=contentShow\&id=1106\&node $\mathrm{id}=13$ $\underline{8}$

Burright, M. A., Hahn, T. B., \& Antonisse, M. J. (2005). Understanding information use in a multidisciplinary field: A local citation analysis of neuroscience research. College \& Research Libraries, 66(3), 198-210.

Ding, Y., Chowdhury, G. G., \& Foo, S. (2000). Journal as markers of intellectual space: Journal co-citation analysis of information Retrieval area, 1987-1997. Scientometrics, 47(1), 55-73. Retrieved December 5, 2009 from SpringerLink database.

Frohlich, C. \& Resler, L. (2001). Analysis of publications and citations from a geophysics research institute. Journal of the American Society for Information Science and Technology, 52(9): 701-713. Retrieved January 15, 2009 from Wiley database.

Gross, P. \& Gross, E. (1927). College libraries and chemical education. Science, 66: 1229-1234, October 1927.

JCR - Journal Citation Reports (2008). Retrieved January 1, 2009 from http://apps.isiknowledge.com/JCR

Narin, F. (1976). Evaluative bibliometrics. (pp. 1): Computer Horizon. Retrieved December 1, 2009 from http://www.conceptsymbols.com/narin/narin_1975_eval-bibliometrics_images.pdf

Ozerdem, A. (1999). Tiles, taps and earthquake-proofing: lessons for disaster management in Turkey. Environment and Urbanization, 11(2), 177-179. Retrieved November 31, 2009 from SAGE Database.

Qiu, H., \& Chen, Y. F. (2009). Bibliometric analysis of biological invasions research during the period of 1991 to 2007. Scientometrics, 81(3), 601-610. Retrieved December 1, 2009 from SpringerLink database.

Thomson Reuters. (2007). Web of Science 8.0. Retrieved December 2, 2009 from http://science.thomsonreuters.com/m/pdfs/mgr/ws-wos-8-0-0807.pdf

Thomson Reuters. (2010). The Thomson Reuter's impact factor. Retrieved January 4, 2009 from http://thomsonreuters.com/products_services/science/free/essays/impact_factor/

Tonta, Y., \& Al, U. (2006). Scatter and obsolescence of journals cited in theses and dissertations of librarianship. Library \& Information Science Research, 28(2), 281-296. Retrieved November 27, 2009 from http://yunus.hacettepe.edu.tr/ tonta/yayinlar/tonta-al-lisr-2006.pdf

T.R. Prime Ministry State Planning Organization. (1999). Depremin ekonomik ve sosyal etkileri (Economic and social effects of earthquake) (pp. 3-4). Prime Ministry State Planning Organization Report.

Trifunac, M. D. (2006a). A note on publication and citation rates of female academics in earthquake engineering. Soil Dynamics and Earthquake Engineering, 26(11), 1063-1075. Retrieved November 30, from ScienceDirect database.

Trifunac, M. D. (2006b). On citation rates in earthquake engineering. Soil Dynamics and Earthquake Engineering, 26(11), 1049-1062. Retrieved November 30, from ScienceDirect database.

Uçak, N. \& Al, U. (2009a). Bilimsel İletişimin Zamana Göre Değişimi: bir atıf analizi çalışması (Changes in scholarly communication over time: a citation analysis study). Bilgi Dünyast, 10(1): 1-22, April 2009. Retrieved December 2, 2009 from http://www.unak.org.tr/BilgiDunyasi/gorusler/2009/cilt10/sayi1/1-22.pdf 
Uçak, N. \& Al, U. (2009b). The differences among disciplines in scholarly communication: a bibliometric analysis of theses. Libri, 59(3): 166-179, September 2009. Retrieved November 30, 2009 from http://yunus.hacettepe.edu.tr/ umutal/publications/libri.pdf

Uzun, A., Menard, A., \& Ozel, M. E. (1993). Citation status of Turkish physics publications in foreign-journals - a global analysis. Scientometrics, 28(1), 79-87. Retrieved November 28, 2009 from SpringerLink database.

Web of Science (2010). Retrieved April 27, 2010 from http://apps.isiknowledge.com

Zhang, Y. (1998). The impact of Internet-based electronic resources on formal scholarly communication in the area of library and information science: a citation analysis. Journal of Information Science, 24(4), 241-254. 